\title{
Exploring the Contribution of Energy Price to Carbon Emissions in African Countries
}

\author{
Bamanga Umar \\ Department of Banking and Finance \\ School of Management and Information Technology \\ Modibbo Adama University of Technology \\ Yola Adamawa State, Nigeria \\ Email: bamanga32@gmail.com
}

\author{
Md. Mahmudul Alam* \\ School of Economics, Finance \& Banking \\ Universiti Utara Malaysia \\ Sintok, Kedah, Malaysia \\ Email: rony000@gmail.com
}

\author{
Abul Quasem Al-Amin * \\ Department of Geography and Environmental Management \\ University of Waterloo \\ Waterloo, ON Canada \\ Email: qalamin@uwaterloo.ca \\ *corresponding author
}

\section{Citation Reference:}

Umar, B., Alam, M.M. \& Al-Amin, A.Q. (2021). Exploring the contribution of energy price to carbon emissions in African countries. Environmental Science and Pollution Research, 28(2), 1973-1982. (0nline) https://doi.org/10.1007/s11356-020-10641-2

This is a pre-publication copy.

The published article is copyrighted by the publisher of the journal. 


\title{
Exploring the Contribution of Energy Price to Carbon Emissions in African Countries
}

\begin{abstract}
The increasing level of greenhouse gas carbon emission currently exacerbates the devastating effect of global warming on the Earth's ecosystem. Energy usage is one of the most important determinants that is increasing the amount of carbon gases being released. Simultaneously, the level of energy usage is derived by the price and therefore, this study examines the contribution of energy price to carbon gas emissions in thirteen African nations for the period spanning 1990 to 2017. It does this by utilizing the Cross-sectional Dependence (CD), Augmented Mean Group (AMG) and Pooled Mean Group (PMG) panel modelling methods. The findings of the AMG model suggest that a $1 \%$ increase in energy price leads to a $0.02 \%$ decerease in carbon emission. The results further reveal that a $1 \%$ increase in energy intensity and technological innovation lead to $0.04 \%$ and $3.65 \%$ increase in carbon emission, respectively, in the selected African countries. Findings will help policymakers to implement effective energy price policies to reduce carbon emissions and achieve sustainable development goals especially in the emerging economies of Africa.
\end{abstract}

Keywords: Africa, Energy price, Carbon emissions, Augmented mean group, Pooled Mean Group (PMG), Cross-sectional Dependence (CD), Sustainable development

\section{Introduction}

The increasing volume of greenhouse carbon emissions has reignited the debate on the consequences of environmental degradation. Carbon emissions now constitute an inordinate challenge to the achievement of sustainable development goals globally. Hence, extreme weather, which is a symptom of overarching climatic changes, is a threat to human health and the environment. Climate change has been threatening the basic elements of human life such as access to water, health food security and the use of natural resources. Thus, a transition to a low-carbon environment needs to be developed by both academics and regulators to unlock the potential of attaining a 'greener' economy.

Despite measures to mitigate global warming, the report of the International Energy Outlook (2017) revealed that the global energy-related $\mathrm{CO}_{2}$ production rose from $1.4 \%$ to 32.5 gigatons as of 2017, thereby representing a very high statistic. The significant rise indicates inadequate political will in addressing the climate change challenges globally. Chen, Wang, Cui, Huang, and Song (2018) reveal that an upsurge in carbon emissions is the main cause of global warming while Paramati, Mo, and Gupta (2017) posit that the majority of $\mathrm{CO}_{2}$ production arises from burning of fossil fuels consisting of coal and gas. These sources deplete the quality of the environment. However, experts have recommended carbon price as a cost-effective and indispensable policy tool for decarbonisation. That is, a well-designed carbon price is necessary for mitigating the increasing greenhouse carbon emissions and for fostering growth (Baranzini, Weber, Bareit, \& Mathys, 2013; Stiglitz, Sen, \& Fitoussi, 2017).

Implementation of carbon pricing policies can accelerate the world's transition to low-carbon and climate-resilient economies. Recently, the study by Lin and Jia (2019) suggests that low energy prices weaken the capacity of the carbon market to reduce emissions while a higher energy price leads to a higher reduction of $\mathrm{CO}_{2}$ emissions. Needless to say, a high energy price is expected to affect $\mathrm{CO}_{2}$ emissions by penalising firms that use more carbon-intense fuels through the increase in their input cost. Therefore, there is a need for a policy framework in 
taking environmental decision to attain sustainable development. However, understanding the potential factors affecting $\mathrm{CO}_{2}$ emissions in Africa is necessary to promote sustainable economic development. Yamineva and Liu (2019) assert that black carbon threatens human health and is a global leading cause of mortality. Hence, carbon emissions mitigation policies are necessary for attaining sustainable development. To be more specific, taking appropriate measures in addressing environmental degradation on the African continent become imperative due to the harsh climatic condition and density population. This is necessary as Chakamera and Alagidede (2018) reveal that Africa is mainly a coal energy-driven continent with low renewable energy, while the low supply of electricity is affecting the operational costs of small and medium-sized businesses. The continent is characterised by an inadequate supply of energy since many firms depend on the widespread use of gasoline generators releasing a large amount of carbon emissions.

Although there is a rising concern on how to address the challenges confronting the environment due to climate change, it is worth noting the few existing empirical studies done in Africa, where the predictive power of energy price in mitigating carbon emissions has been overlooked. The focus of the previous literature is on how energy consumption (Al-mulali, Sab, \& Fereidouni, 2012; Bouznit \& Pablo-Romero, 2016; Chakamera \& Alagidede, 2018; Esso \& Keho, 2016), renewable energy (Ben Jebli, Ben Youssef, \& Ozturk, 2015) financial development (Adom, Kwakwa, \& Amankwaa, 2018), GDP (Abid, 2016), energy intensity (Shahbaz, Solarin, Sbia, \& Bibi, 2015) and industrialisation (Asane-Otoo, 2015; Lin, Omoju, \& Okonkwo, 2015) predict $\mathrm{CO}_{2}$ emissions in Africa.

Therefore, this study selects 13 African countries, based on data availability, to investigate the empirical nexus between carbon emission and energy price. However, to overcome the contemporaneous correlation in the data, this study utilises the Pesaran (2007) secondgeneration unit root test, which assumes Cross-sectional dependence (CD) across the sample countries and employed the Augmented mean group (AMG) model proposed by Eberhardt and Bond (2009) and Eberhardt and Teal (2010). This model has the advantage of being able to overcome the presence of contemporaneous correlation problems in panel data. It has been argued that a lack of considering $\mathrm{CD}$ due to undetected common elements can lead to estimating a spurious regression (Pesaran, 2004). Therefore, the findings of this study will make it possible for policymakers to better assimilate the predictive power of energy price on $\mathrm{CO}_{2}$ emissions in Africa.

\section{Literature Review and Theoretical framework}

Understanding the potential drivers of greenhouse carbon emissions is crucial to achieving sustainable development goals. This study generally reviews previous literature that investigates the factors affecting carbon dioxide emissions. Despite more emphasis being placed on how energy price predicts carbon emissions globally, little attention is paid to the African region (Table 1). For example, Hammoudeh, Nguyen, and Sousa (2014) found that energy price exerts a different effect on $\mathrm{CO}_{2}$ production in the United States depending on the market spectrum. On the other hand, Li et al. (2018) use provincial panel data from China and their findings reveal that energy price has an indirect effect on carbon emissions through energy structure, energy efficiency, industrial structure and economic development. 
Table 1: Summary of literature findings on African Countries

\begin{tabular}{|l|l|l|l|l|l|l|l|l|l|l|l|l|l|}
\hline \multirow{2}{*}{$\begin{array}{l}\text { Drivers of Carbon } \\
\text { Emissions }\end{array}$} & \multicolumn{7}{|c|}{ Selected Empirical Studies } \\
\cline { 2 - 13 } & {$[1]$} & {$[2]$} & {$[3]$} & {$[4]$} & {$[5]$} & {$[6]$} & {$[7]$} & {$[8]$} & {$[9]$} & {$[10]$} & {$[11]$} \\
\hline Energy consumption & & $(+)$ & & & $(+)$ & $(+)$ & $(+)$ & & & & \\
\hline Energy intensity & & & $(+)$ & & & & & () & $(+)$ & & \\
\hline Democracy & $(-)$ & & & & & & & & & & $(-)$ \\
\hline GDP & () & $(+)$ & & () & $(+)$ & & $(+)$ & $(+)$ & $(+)$ & & \\
\hline Urbanisation & & () & & & & & & & & & \\
\hline Industrialisation & & & & & & & & $(-)$ & & & \\
\hline Population & & & & & & & & $(+)$ & & & \\
\hline Renewable energy & & & & () & & & & & & () & $(-)$ \\
\hline $\begin{array}{l}\text { Non-renewable } \\
\text { energy }\end{array}$ & & & & & & & & & & $(+)$ & \\
\hline Exports & & & & $(+)$ & $(-)$ & & & & & & \\
\hline Imports & & & & $(-)$ & $(+)$ & & & & & & \\
\hline Regulatory quality & $(+)$ & & & & & & & & & & \\
\hline
\end{tabular}

Note: The symbol in the parentheses stand for the nexus between carbon emissions and their drivers in Africa while () indicates no significant relationship at the conventional (1\%, 5\% or $10 \%)$ levels.

For the studies, [1] =Abid (2016), [2] = Ali, Law, and Zannah (2016), [3] =Asane-Otoo (2015), [4] = Ben

Jebli et al. (2015), [5] = Bouznit and Pablo-Romero (2016), [6] = Chakamera and Alagidede (2018), [7] = Esso and Keho (2016), [8] = Lin et al. (2015), [9] = Shahbaz et al. (2015), [10] = Nathaniel and Iheonu

(2019) and [11) = Adams and Acheampong (2019).

Needless to say, there are studies on how energy price shocks predict carbon emission. Zhang et al. (2019) suggest that energy price contributes to a reduction of $\mathrm{CO}_{2}$ emissions in China while Tvinnereim and Mehling (2018) suggest that carbon pricing is the most cost-effective tool for carbon emissions reduction. Similar findings on the impact of a carbon price are obtained by Martinsen, Krey, and Markewitz (2007), Zhou and Li (2019) and Verbič, Filipović, and Radovanović (2017), respectively, for Germany, China and Europe. This implies the importance of price increase for deep decarbonisation and sustainable growth. Despite the evidence of negative energy price-carbon emission nexus, the findings of Valizadeh, Sadeh, Javanmard, and Davodi (2017) suggest a positive effect of energy price on energy consumption in Iran. This is in line with Linn (2009) who indicates that links between supply and demand have an effect on energy price shocks.

Nevertheless, the studies undertaken by Sun, Ding, Fang, Zhang, and Li (2019) and Triguero, Moreno-Mondéjar, and Davia (2014) for China and Europe, respectively, reveal that energy price does not matter for predicting changes in $\mathrm{CO}_{2}$ emission. The findings reported by Lee and Chong (2016) also suggest that energy prices can only be an effective tool in managing carbon emissions if the price is higher since the lower price has no significant impact on reducing carbon emissions in the United States. In other words, the aforementioned studies indicate that energy price was not as important as previously believed in driving carbon emissions. This implies that investors and policymakers might have diverted their interest in energy prices to other factors to predict changes in environmental pollution.

Furthermore, there are empirical studies on the effectiveness of the emissions trading system (ETS) in curbing environmental degradation. For example, Cheng, Dai, Wang, Zhao, and Masui (2015) contend that the ETS has the potential to reduce sulphur $\left(\mathrm{SO}_{2}\right)$ emissions and nitrogen oxide (NOx) emissions in China's Guangdong province. The ETS is described as one of the most cost-effective mechanisms for mitigating carbon emissions (Cui, Fan, Zhu, \& Bi, 2014; Lin \& Jia, 2019). Therefore, the ETS can be an effective policy tool for achieving climate change mitigation target, protecting human health and the ecosystem at large. It is worth 
stressing that the ETS is an active trading product in the carbon finance market. A further review uncovers the efficiency of the emissions trading system as Zhou and Li (2019) argue that the ETS is an internationally recognised financial policy tool for attaining a carbon emissions reduction target. Schmalensee and Stavins (2015) disclose that the European Union's (EU) capand-trade system is the world's largest multi-country emissions trading system for addressing environmental problems. Consequently, the implementation of the ETS can alleviate the welfare cost/loss of greenhouse carbon emissions.

Apart from the effect of energy/carbon price on carbon emissions, empirical studies show the other predictive power of energy price. For example, Wang, Wang and Wu (2012) assert that the energy price surprises or exacerbates the price of agricultural products in China, while Valadkhani, Babacan, and Dabir-Alai (2014) discovered that energy price shocks influence tradeable and capital-demanding sectors more than the non-tradeable sectors in Australia. Furthermore, some analyses discovered a multi-dimensional effect of energy prices. Hang and $\mathrm{Tu}$ (2007) suggest that the energy price leads to a decline in energy intensity, yet it adds more burdens to vulnerable households in China. A decade ago, the findings of Yuan, Liu, and $\mathrm{Wu}$ (2010) indicate a positive long-run and negative short-run impact of energy price on energy consumption in China. It implies that a higher energy price is necessary to limit energy consumption to a sustainable level.

Moreover, it is found that energy intensity and carbon emissions are positively connected in the Sub-Saharan economies (Shahbaz et al., 2015). A similar finding was disclosed recently by Chen et al. (2018) in the Organisation of Economic Co-operation and Development (OECD) nations. However, the interaction between industrialisation and $\mathrm{CO}_{2}$ emissions reveals mixed findings, given that Asane-Otoo (2015) found industrialisation exerts a positive effect on $\mathrm{CO}_{2}$ emissions in Africa while Lin et al. (2015) report no significant influence of industrialisation on carbon emissions in Nigeria. A further assessment of the empirical literature discloses the predictive power of technological innovation on $\mathrm{CO}_{2}$ emissions. For example, Wang, Wang, and Zhou (2018) disclose that technology plays a crucial role in reducing the amount of carbon emissions in the Chinese provinces. The long-standing issue of climate change can be resolved by applying innovative structural transformation that will improve the ecosystem. Similarly, the findings of Fan and Hossain (2018) suggest a unidirectional connection from technological innovation to $\mathrm{CO}_{2}$ emissions in India and China.

In contrast, Zhao, Ma, and Yang (2013) found unidirectional causality running from $\mathrm{CO}_{2}$ emissions to technological innovation. The findings reported by Irandoust (2016) indicate a unidirectional connection between technological innovation to renewable energy in Nordic nations. The study concluded that innovation performs a pivotal role in the renewable energygrowth relationship. However, some research reveals innovation does not reduce environmental degradation. In a recent investigation, the results of $\mathrm{Yu}$ and $\mathrm{Du}$ (2019) suggest that the introduction of innovation inhibits $\mathrm{CO}_{2}$ emissions in China's 30 provinces. A few years earlier, Ali et al. (2016) found that technological innovation has no substantial effect on reducing $\mathrm{CO}_{2}$ emissions in Nigeria while Fan, Liu, Wu and Wei (2006) suggest that the effect of technology on carbon production differs at different levels of development. Consequently, it could be argued that nations can take different measures with their economic development level when formulating the relevant policies.

The theoretical link between economic growth and environmental quality can be traced back to the Grossman and Kruege (1995) environmental kuznets curve (EKC) hypothesis. The EKC was mainly on how per-capita income growth relates to environmental degradation. To be more 
specific, the model postulates an inverted U-shape nexus between income inequality and economic development. This theory predicts that, at an early stage of economic development, there is abundant natural resources and waste generation. As the economy takes shape with activities, there will be a significant depletion of natural resources and waste accumulation. Thus, the inverted U-shape nexus can be attributed to a high level of development with enforcement of environmental regulation and technological improvement. In summary, the EKC hypothesis postulates that, in the beginning, the environmental quality will deteriorate when income rises and eventually rise due to an increase in income in the long-run. Therefore, it is expected that $\mathrm{CO} 2$ emission will rise at an early stage and decrease in the end.

There are empirical studies that examine the validity of the EKC hypothesis with mixed findings. For example, Pata (2018) examine the relationship between GDP and CO2 emission in Turkey and the findings are in line with the EKC hypothesis revealing the inverted U-shape nexus. Similarly, Shahbaz et al. (2015) test for the validity of the hypothesis and found the existence of a negative link between real GDP and CO2 in Sub-Saharan Africa. The study of Ali et al. (2016) investigated the dynamic effect of GDP growth on CO2 emission in Nigeria and their findings uncover that the $\mathrm{CO} 2$ emission per capita rises with the increase in the GDP per capita growth. In addition, Al Mamun et al. (2016) examine the link between economic growth and $\mathrm{CO} 2$ emission using a panel of 136 economies. Apart from the high-income OECD economies, the findings suggest the validity of the ECK in all the other regions.

Therefore, linking the relationship between energy price and carbon dioxide emission to the EKC theoretical prediction will offer a valuable theoretical insight and augment empirical literature to promote sustainable development. Base on the theretical prediction, carbon emission can be effectively abated by raising energy price. In other words, an increase in energy price relative to the price of its substitute can lead to reduction in demand. An increase in energy price can induce producers to substitute consumption of fossil fuel with cheaper and efficient alternative source of energy ( $\mathrm{Li}$, Fang \& He, 2020). This can subsequemtly lead to a reduction in fossil fuel demand and green house carbon emission.

Moreover, the nexus between energy intensity, technological innovation and carbon emission and be linked to the EKC theoretical prediction. There are empirical studies that reveal a significant relationship between energy intensity and carbon emission. For example, Shahbaz et al. (2015) found that energy intensity has a positive impact on carbon emission in SSA counties similar to the Chen et al.(2018) study that reports that energy intensity is one of the main determinants of carbon emission in the OECD countries. For the tecnological innovationcarbon emission nexus, the empirical findings of Fan and Hossain (2018) reveal a unidirectional causality from technological innovation to carbon emission. This indicate that the long standing issue of green house carbon emission can be effectively addreesed using new technologies.

Therefore, this study identified two major streams on the contribution of energy development linked to carbon emissions in African countries, namely (i) Environmental Kuznets Curve and linked between the contribution of energy price to carbon emissions to know whether there is a link with significant nexus between energy price and carbon emissions, and (ii) Environmental Kuznets Curve and linked between the contribution of energy intensity and technological innovation to understand whether there is a link with significant nexus between technological innovation and carbon emissions. With this background this study identified the following research questions: 
1. Is there any relationship with the Environmental Kuznets Curve and linked between the contribution of Energy Price to Carbon Emissions in African Countries (e.g. significant nexus between energy price and carbon emissions)?

2. Is there any relationship Environmental Kuznets Curve and linked between the contribution of energy intensity and technological innovation ( e.g. significant impact on carbon emissions?

The research questions aimed to be answered in the study by utilizing the Cross-sectional Dependence (CD), Augmented Mean Group (AMG) and Pooled Mean Group (PMG) panel modelling methods and the outcomes aimed to be useful for policymakers to implement effective energy price policies to reduce carbon emissions and achieve sustainable development goals in the African emerging economies.

\section{Methodology}

\subsection{Sources of Data and Measurement of Variables}

The data for this research are retrieved from the World Development Indicators (WDI, 2016) database. The thirteen (13) African countries forming the sample of this study are Algeria, Egypt, Ethiopia, Kenya, Madagascar, Malawi, Mauritius, Morocco, South Africa, Sudan, Tanzania, Tunisia, and Zambia. These countries are selected based on data availability and limited research findings in the continent on the energy price-carbon emission nexus. In other words, the selection of the 13 countries (representing 24 percentage of the total African countries) is purely based on data availability and insufficient literature on how energy price predicts carbon emission in Africa. In fact, the African region has been less considered in the literature on how environmental policies mitigate carbon emission. To be more specific on the measurement of variables, the per capita $\mathrm{CO}_{2}$ emissions represent the dependent variable of this study. Due to the unavailability of energy price data for most developing countries, the previous empirical literature (Lean and Smyth, 2010; Mahadevan and Asafu-Adjaye, 2007; Tang and Tan, 2013) also used Consumer Price Index (CPI) to proxy for energy price as the main independent variable of this study. Mahadevan and Asafu-Adjaye (2007) further contend that the energy-intensive industries are subsidized by government thus facing different prices hence the use of energy sources vary in different economies. For the model's control variables, energy intensity, a total number of patent applications and per capita actual GDP respectively stand for energy intensity, technological innovation, and GDP. All the variables are converted to their natural log before employing the method of analysis employed in this study.

\subsection{Cross-sectional dependence and second-generation unit root test}

This study utilises the Pesaran (2004) Cross-sectional dependence (CD) analysis to examine the contemporaneous correlation among the sample countries. It also determines the appropriate unit root test to be used in checking data stationarity and the cointegrating techniques for the sample countries. The CD test has a null hypothesis of cross-sectional dependence. It is argued that lack of considering cross-sectional dependence due to unnoticed ordinary factors can lead to estimating a spurious regression (Al Mamun et al., 2016; Pasaran, 2004). Thus, the CD analysis is estimated utilising the following equation:

$C D=\frac{T N(N-1) 1 / 2}{2} \hat{p}$ 
Where $\hat{\mathrm{p}}=\left[\frac{2}{\mathrm{~N}(\mathrm{~N}-1)}\right] \sum_{\mathrm{i}=1}^{\mathrm{N}-1} \sum_{\mathrm{k}=\mathrm{i}+1}^{\mathrm{N}} \hat{\mathrm{p}} \mathrm{ik}$ thus $\hat{\mathrm{p}} \mathrm{ik}$ shows the pairwise cross-sectional correlation coefficient of the residuals that is gotten from the ADF regression while the $\mathrm{N}$ and $\mathrm{T}$, respectively, stand for cross-section and time dimension.

In addition to the CD statistics above, the following equation serves to assess the cross-sectional $\mathrm{ADF}$ regression with a time trend:

$\Delta y_{i t}=\alpha_{i}+T_{i}+\beta_{i} y_{i t-1}+\pi_{i} \bar{y}_{t-1}+\varphi_{i} \Delta \bar{y}_{t}+\varepsilon_{i t}$

Where $t=1, \ldots \ldots ., \mathrm{T}, \mathrm{i}=1, \ldots \ldots \ldots, \mathrm{N}$ and $\bar{y}_{\mathrm{t}}$ shows the cross-sectional mean of $\mathrm{y}_{\mathrm{it}}$. Therefore, taken into account the cross-sectional mean reduces the effect of contemporaneous correlation among the $y_{i t}$.

The null hypothesis of equation 2 is $\mathrm{H} 0: \beta_{i}=0$ for all $\mathrm{i}$ while the alternative hypothesis is Ha: $\beta_{i}<0$ for some i. Hence the Pesaran (2007) method provides the cross-sectional augmented panel unit root (CIPS) test statistics as follows:

$\operatorname{CIPS}(N, T)=N^{-1} \sum_{i=1}^{N} t_{i}(N, T)$

Here, the $t_{i}(N, T)$ shows the t-statistics of $\beta_{i}$. Therefore, the CD test and the CIPS, respectively, are used in this study to: firstly, determine the presence/absence of contemporaneous correlation problem; and secondly, test for the unit root properties of panel series having a cross-sectional dependence problem. It was disclosed that ignoring the contemporaneous correlation of regression disruptions over time can cause a biased statistical implication (Hoechle, 2007). The author further states the inappropriateness of assuming that the disruptions of a panel model are cross-sectionally independent. The reasons for the possibility of cross-section dependence are not farfetched as herd behaviour, social norms and psychological behaviour patterns cannot be quantitatively measured.; For these reasons they are considered to be unobserved common factors. Hence, the cross-sectional dependence test and second-generation unit root tests are prerequisites for estimating the Augmented mean group (AMG) model.

\subsection{Augmented Mean Group (AMG) Model}

The Augmented mean group (AMG) model was developed by Eberhardt and Teal (2010) as an option to the normal Correlated effect mean group (CCEMG) of Pesaran (2006) where the unitspecific parameters of the AMG are averaged across the panel members. Unlike the mean group (MG) model, the AMG includes a common dynamic effect where a combined regression model augmented with year dummies is projected by the first variation common least square. In other words, the pooled estimation of the AMG is conducted using time dummies in the first difference. In a related study, Atasoy (2017) contends that the conventional panel models might be inconsistent if the cause of a cross-section reliance correlates with regressors. Therefore, the estimation of the AMG model is appropriate since it captures cross-section dependence where the model allows for unobserved correlation across panel members.

Moreover, the model employs a two-step method to estimate a dynamic effect and to account for a contemporaneous correlation. The augmented country regression model comprises a cointegration relation that is heterogeneous across the cross-section. The model is expressed as follows: 
$\Delta y_{i t}=\grave{b} \Delta x_{i t}+\sum_{t=2}^{T} m_{t} \Delta D_{t}+\varepsilon_{i t}$

Here, $m_{t}=\mu_{t}$

$y_{i t}=\alpha_{i}+\dot{b}_{l} x_{i t}+m_{i} t+d_{i} \mu_{l t}^{\prime}+\varepsilon_{i t}$

Equation 4 stands for a standard OLS regression with time dummies while the $\boldsymbol{\Delta}$ represents difference operator, $\mathrm{m}_{\mathrm{t}}$ is the coefficient of time dummies or common dynamic effect. Also, the group-specific parameters of the AMG model are averaged across entities where each regressor contains an intercept that obtains the time-invariant static effect. Following Pesaran and Smith (1995) mean group approach, the following equation is utilised to approximate the mean group of the AMG model:

$\hat{b} A M G=N^{-1} \sum_{i} b_{l}$

Furthermore, to assess the robustness of the findings derived from AMG estimation, this study further checks the model by estimating Pool Mean Group (PMG) model.

\section{Empirical Findings}

To accomplish the goal of the present study, this section contains the results of the cross-section dependence $(\mathrm{CD})$, second-generation unit root test as well as the results of the augmented mean group (AMG) model. The results of the CD analysis are depicted in Table 2 below.

Table 2: CIPS Cross-sectional Dependence Test

\begin{tabular}{lccc}
\hline Variables & CD-test & Corr & Abs (Corr) \\
\hline $\mathrm{CO}_{2}$ & -0.44 & -0.009 & 0.348 \\
$\mathrm{ENP}$ & $41.75^{* * *}$ & 0.951 & 0.951 \\
$\mathrm{ENI}$ & $16.25^{* * *}$ & 0.366 & 0.518 \\
$\mathrm{TEC}$ & $7.76^{* * *}$ & 0.178 & 0.571 \\
$\mathrm{GDPc}$ & $31.39^{* * *}$ & 0.716 & 0.806 \\
\hline
\end{tabular}

Note: The asterisk *** denotes the $1 \%$ level of significance.

The outcomes of the Pesaran CIPS test in Table 2 suggest the existence of cross-sectional dependence in the errors under the assumption of heterogeneity among the selected African countries. Apart from $\mathrm{CO}_{2}$, the results show all the variables are statistically significant so the null hypothesis of cross-sectional independence is rejected for this study. The implication is that changes in each of the variables in one country would affect the other sample countries. Therefore, it is essential to handle the contemporaneous correlation in the data due to the potential external shocks. The evidence for dependence among the sample countries justifies the need for testing a second-generation unit root test and the results are documented in Table 3 below.

Based on the result of the $\mathrm{CD}$ analysis, this paper employs the CIPS second-generation unit root test to check for the potential hidden features of the data using constant and trend specifications. The outcomes as depicted in Table 3 reveal that all the variables are having unit root problems at a certain level though they become stationary after taking the first variation. It is worth noting 
here that the outcomes of the CD and CIPS are necessary for estimating the Eberhardt and Teal (2010) augmented mean group (AMG) model. It will help to examine the potential drivers of $\mathrm{CO}_{2}$ in the selected African countries.

Table 3: Cross-sectional augmented IPS unit root test

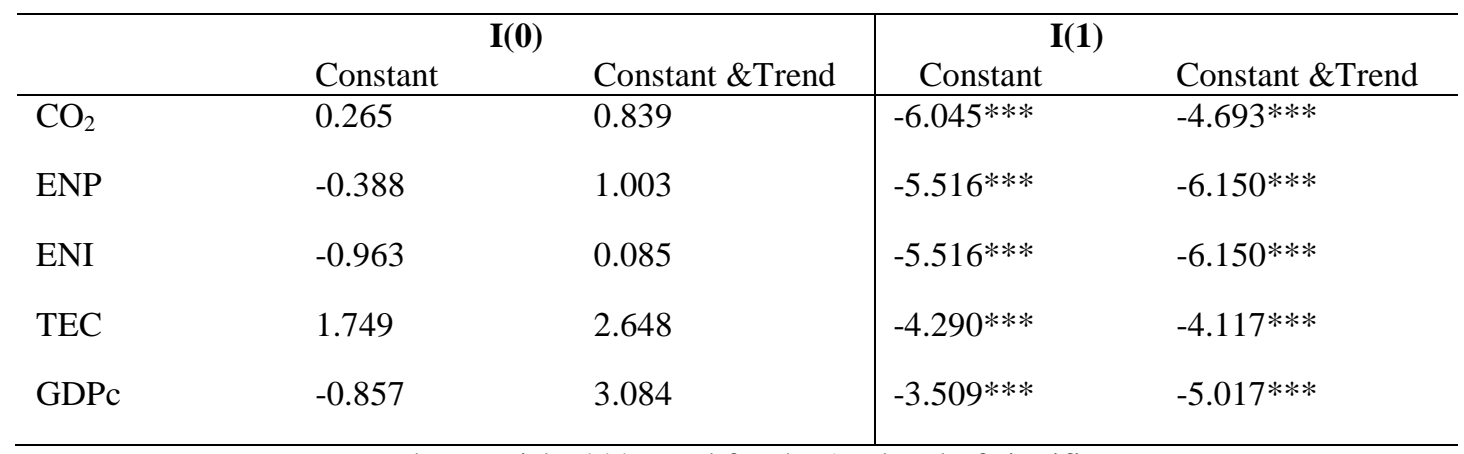

Note: The asterisks *** stand for the $1 \%$ level of significance.

As presented in Table 4, the findings from the augmented mean group (AMG) model reveal a negative and statistically significant relationship between the ENP and $\mathrm{CO}_{2}$ emissions. Specifically, a 1 percent increase in ENP will lead to a 0.002 percentage decrease in $\mathrm{CO}_{2}$ emissions at a 5 percent level of significance. This evidence indicates that energy price is an important driver of carbon emissions in Africa. The negative influence of energy price on carbon production is consistent with the findings of other recent studies (Martinsen et al., 2007; Tvinnereim \& Mehling, 2018) that suggest carbon price is an effective policy tool for achieving decarbonisation. Therefore, a high energy price contributes to a significant reduction in environmental degradation. This demonstrates that a regular increase in energy price has the potential to produce an effective emissions mitigation target. When the output of energy firms is sensitive to a carbon price increase, a higher price can increase the commodity price of the emitting firms and subsequently reduce their consumption. The inverse nexus between energy price and $\mathrm{CO}_{2}$ emissions also confirms the findings of Duan, Mo, Fan, and Wang (2018), who suggest carbon pricing plays a key role in curbing carbon emissions in China.

Table 4: Output of Augmented Mean Group (AMG)

\begin{tabular}{lcccc}
\hline Variable & Coefficient & Std. Error & Z-Statistic & Prob. \\
\hline ENP & $-0.002^{* *}$ & 0.007 & -2.48 & 0.013 \\
ENI & $0.044^{* *}$ & 0.023 & 1.90 & 0.058 \\
TEC & $3.652^{* *}$ & 2.178 & 1.680 & 0.094 \\
GDPc & 2.859 & 2.141 & 1.34 & 0.182 \\
Constant & -28.14 & 18.94 & -1.49 & 0.137 \\
RMSE & 0.062 & & \\
Observation & 240 & & \\
Countries & 13 & & \\
\hline \multicolumn{5}{c}{}
\end{tabular}

Besides, the findings of the control variables of this study are also interesting. To be more precise, the energy intensity (ENI) and technological innovation exert a positive effect on carbon emissions in line with some previous empirical literature (Chen et al., 2018; Shahbaz et al., 2015). Nevertheless, the positive non-significant link among the GDP per capita and $\mathrm{CO}_{2}$ emissions confirms the findings of Ghosh and Kanjilal (2014). They suggest GDP may not be necessary for the reduction of carbon emissions. 
For robustness checks, this paper employs the pooled mean group (PMG) to investigate how carbon emissions respond to changes in energy prices. Interestingly, the results of the test as shown in Table 5 lend support to the main model developed for this study. In other words, the conclusions are coherent with the results of the augmented mean group model. In sum, the impact of energy price on carbon release is sensitive to methodological choices.

Table 5: Output of Pooled Mean Group Model

\begin{tabular}{|c|c|c|c|c|}
\hline Variable & Coefficient & Std. Error & Z-Statistic & Prob. \\
\hline ENP & $-0.004 *$ & 0.001 & -3.31 & 0.001 \\
\hline ENI & $1.491^{*}$ & 0.184 & 8.07 & 0.000 \\
\hline TEC & 0.039 & 0.028 & 1.42 & 0.155 \\
\hline GDPc & $0.214 * *$ & 0.121 & 1.77 & 0.077 \\
\hline ECT & $-0.182 * *$ & 0.096 & -1.90 & 0.058 \\
\hline Constant & $-0.718 * *$ & 0.402 & -1.78 & 0.075 \\
\hline
\end{tabular}

\section{Discussion}

The aim of the study is to investigate the effects of energy on $\mathrm{CO}_{2}$ emissions among 13 African countries. The findings of the AMG model indicate a negative and statistically substantial link among energy price and carbon dioxide production. Energy price is an essential factor of carbon emissions in Africa. This influence is consistent with the findings of some previous literature (Martinsen et al., 2007; Tvinnereim \& Mehling, 2018), which suggest carbon price is an effective policy tool for achieving decarbonisation. The potential explanation of this outcome is that the rate of increase in global warming due to carbon emissions can be mitigated when energy price is taken into consideration. Consistent with the results of the main model (AMG model), the robustness test (PMG model) suggests that energy price is a key driver of carbon emissions in Africa which is consistent with the findings of Duan, Mo, Fan, and Wang (2018). These authors suggested a similar role in curbing carbon emissions in China.

It has remained evident from the literature that the connection among energy and environment change is extremely solid and therefore represents a substantial task for environmental improvement. In most emerging nations, energy pricing is still founded upon political and social reasoning rather than effective market valuing rules. In 1993, the World Bank estimations revealed that emerging nations and developing nations paid more than $\$ 230$ billion per year on energy subsidies (Cao, 2003). For instance, in Poland, Turkey, China and India energy sources like coal have remained hugely subsidised (World Bank, 2000:25). Similarly, Nigeria pays huge amount of money on petroleum subsidies. The consequence of this followed wasteful usage of electricity power as well as providing as a deterrent for managing energy-associated releases. Economical energy valuing will not merely eliminate these value biases but could dramatically lessen the increase in electricity power utilisation and might likewise possibly reduce global carbon production by 10\% (World Bank, 2000:41).

Nevertheless, attempts to tackle the tragedy mutually at the global, local, or state level could be explained as something less than fruitful. For example, on the international stage, executing the different modification processes that are part of the Kyoto Procedure of the UNFCCC has produced partial outcomes in tackling international $\mathrm{CO}_{2}$ productions. The organisation establishes emissions goals that limit the carbon discharges of the EU and 37 developed nations. 
Furthermore, the rule of mutual but distinguished duties creates distinct objectives for these members of industrialised nations, apart from emerging nations such as India and China (Aichele and Felbermayr, 2015). Some influential factors that affect the implementation process is that for first, none of the main pollutants were incorporated (IEA, 2010a).

Alternatively, emerging nations, even though nearly all that endorsed the procedure are less dedicated to carbon dioxide production declines. A crucial strategy problem encountered by most emerging nations is in harmonising the compromise among continuous economic increases and curtailing carbon dioxide energy-associated production methods. The idea in various areas is that $\mathrm{CO}_{2}$ releases constitute a universal contaminant and therefore one nation only decreasing the rate is essentially demonstrating and ineffective practice. This is because aspects of market collapse are prevalent. In case one state reduces its amount of fossil energy burning, it carries the highest price in the form of reducing its economic activity intensity, whilst the advantages of its engagement are enjoyed jointly worldwide. This leads some experts to propose that the determination concerning carbon dioxide reduction must be founded and tolerated by the developed nations who are basically not solely accountable for the preliminary releases of greenhouse gases throughout the industrialised world. This is similar to the augmented amount being produced as a consequence of increasing usage of fossil fuels.

Nevertheless, a successful modification of climate transformation will involve the determination of all nations. The best possible approach for extenuating the effects of weather alteration that occur from energy-associated events would not solely require being extremely inclusive and universal in magnitude. However, these sorts of strategies must be adaptable and flexible to nationwide and domestic circumstances of the specified nation-state. As a result of fast-changing market circumstances, policies can no longer be documents once created and then 'left on the shelf' for several years and are not acted upon. There are exceptional strategies presently in place, yet they do not produce established energy reduction objectives. The explanation rests in the absence of an understanding and emphasis on implementing what can work, which currently is too inadequate, underdeveloped, and unsuitable for ambitious goals that must be achieved.

Looking at things from an economic perspective it is more crucial to endogenise the peripheral costs of greenhouse gases than the prices of local air pollution. Nonetheless, it is uncertain whether an energy price tax would have the required driving impact on energy production in Africa. An alternative method to decreasing greenhouse gas releases is the implementation of a "cap-and-trade" structure. This scheme is already operating in the European Union and may fit the African context. It is unclear, nevertheless, whether the African nations' finance systems can manage the details of a carbon trading scheme and, even more significant, if there will be sufficient regional members to withstand it. As well, many sectors of the African economy particularly transportation sector (predominantly road transport) produce larger quantities of GHGs. Provided that the main energy source still leads the global electricity power mix, the desired goal has led to disputes over whether to focus on environmental protection or economic growth.

Lastly, decreasing energy-associated carbon productions may necessitate a reduction in the quantity of fossil energy utilisation and therefore economic development. This problem has added to the sluggish international, national and local economic activities in tackling the threat of climate change. Although climate change is correlated with heightened fossil energy burning and it is severe, it does necessitate collaborative and inclusive solutions. Sufficient ecological knowledge is necessary to educate the community on the importance of the deteriorating 
atmosphere they are surviving in, and a price will have to be paid for their wellbeing and ability to live in conditions as they currently are. Such information is vital in adding to the public's awareness and might force the public to back ecological policies and degradation prevention regulations. This might encourage all countries to improve their implementation and enforcement of environmental policies.

\section{Conclusions}

One of the main challenges confronting humankind in saving the environment is climate change. Energy usage is one of the most important factors that is accelerating climate change, whereas energy price is one of the leading factors to ascertain energy demand. This paper investigates the contribution of energy price to carbon emissions in the climate change landscape using panel evidence from thirteen African countries. It found a negative and statistically significant relationship between energy price and carbon dioxide emissions and a positive nexus with energy intensity and technological innovation in the African countries. This reveals that energy price is an important determinant of carbon emissions in Africa, but the rest of the world can generalise the importance of energy price to controlling carbon dioxide emissions in the battle against climate change. Future studies can test other parts of the world to investigate what the findings mean in other contexts. Moreover, future study can focus on changing the energy proxy variable such as energy tariffs or crude oil price to validate the findings of the study. Based on the conclusion, this paper recommends that policymakers concentrate on energy price as a mechanism for controlling and mitigating the adverse effects of carbon emissions. The guidelines included amendments to wasteful energy valuing, burden of carbon production levies, supporting financing and subsidising forms of renewable energy, and creating new community understanding about what is needed to protect the environment.

\section{References}

Abid, M. (2016). Impact of economic, financial, and institutional factors on CO2 emissions: Evidence from Sub-Saharan Africa economies. Utilities Policy, 41, 85-94.

Adams, S., \& Acheampong, A. O. (2019). Reducing carbon emissions: The role of renewable energy and democracy. Journal of Cleaner Production, 240, 118245.

Adom, P., Kwakwa, P., \& Amankwaa, A. (2018). The long-run effects of economic, demographic, and political indices on actual and potential $\mathrm{CO}_{2}$ emissions. Journal of Environmental Management, 218, 516-526.

Aichele, R., Felbermayr, G., 2015. Kyoto and carbon leakage: an empirical analysis of the carbon content of bilateral trade. The Review of Economics and Statistics, 97, 104-115.

Al Mamun, M., Sohag, K., Samargandi, N., \& Yasmeen, F. (2016). Does remittance fuel labour productivity in Bangladesh? The application of an asymmetric non-linear ARDL approach. Applied Economics, 48(50), 4861-4877.

Ali, W., Abdullah, A., \& Azam, M. (2016). The dynamic linkage between technological innovation and carbon dioxide emissions in Malaysia: An autoregressive distributed lagged bound approach. International Journal of Energy Economics and Policy, 6(63), 389-400.

Al-mulali, U., Sab, C., \& Fereidouni, H. (2012). Exploring the bi-directional long run relationship between urbanization, energy consumption, and carbon dioxide emission. Energy, 46(1), 156-167.

Asane-Otoo, E. (2015). Carbon footprint and emission determinants in Africa. Energy, 82, 426435. 
Atasoy, B. S. (2017). Testing the environmental Kuznets curve hypothesis across the US: Evidence from panel mean group estimators. Renewable and Sustainable Energy Reviews, 77, 731-747.

Baranzini, A., Weber, S., Bareit, M., \& Mathys, N. (2013). The causal relationship between energy use and economic growthin Switzerland. Energy Economics, 36, 464-470.

Ben Jebli, M., Ben Youssef, S., \& Ozturk, I. (2015). The role of renewable energy consumption and trade: environmental Kuznets curve analysis for Sub-Saharan Africa countries. African Development Review, 27(3), 288-300.

Bouznit, M., \& Pablo-Romero, M. (2016). $\mathrm{CO}_{2}$ emission and economic growth in Algeria. Energy Policy, 96, 93-104.

Cao, X. (2003), Climate change and energy development: Implications for developing countries. Resources Policy, 29, 61-67.

Chakamera, C., \& Alagidede, P. (2018). Electricity crisis and the effect of CO2 emissions on infrastructure-growth nexus in Sub Saharan Africa. Renewable and Sustainable Energy Reviews, 94, 945-958.

Chen, J., Wang, P., Cui, L., Huang, S., \& Song, M. (2018). Decomposition and decoupling analysis of CO2 emissions in OECD. Applied Energy, 231, 937-950.

Cheng, B., Dai, H., Wang, P., Zhao, D., \& Masui, T. (2015). Impacts of carbon trading scheme on air pollutant emissions in Guangdong Province of China. Energy for Sustainable Development, 27, 174-185.

Cui, L., Fan, Y., Zhu, L., \& Bi, Q. (2014). How will the emissions trading scheme save cost for achieving China's 2020 carbon intensity reduction target? Applied Energy, 136, 1043 1052.

Duan, H., Mo, J., Fan, Y., \& Wang, S. (2018). Achieving China's energy and climate policy targets in 2030 under multiple uncertainties. Energy Economics, 70, 45-60.

Eberhardt, M., \& Bond, S. (2009). Cross-section dependence in nonstationary panel models: a novel estimator. Munich Personal RePEc Archive.

Eberhardt, M., \& Teal, F. (2010). Productivity Analysis in Global Manufacturing Production.

Esso, L., \& Keho, Y. (2016). Energy consumption, economic growth and carbon emissions: Cointegration and causality evidence from selected African countries. Energy, 114, 492497.

Fan, H., \& Hossain, M. I. (2018). Technological Innovation, Trade Openness, CO2 Emission and Economic Growth: Comparative Analysis between China and India. International Journal of Energy Economics and Policy, 8(6), 240-257.

Ghosh, S., \& Kanjilal, K. (2014). Long-term equilibrium relationship between urbanization, energy consumption and economic activity: Empirical evidence from India. Energy, 66, 324-331.

Grossman, M., \& Kruege, B. (1995). Economic growth and the environment. The Quarterly Journal of Economics, 110(2), 353-377.

Hammoudeh, S., Nguyen, D. K., \& Sousa, R. M. (2014). Energy prices and $\mathrm{CO}_{2}$ emission allowance prices: A quantile regression approach. Energy Policy, 70, 201-206.

Hang, L., \& Tu, M. (2007). The impacts of energy prices on energy intensity: Evidence from China. Energy Policy, 35(5), 2978-2988.

Hoechle, D. (2007). Robust standard errors for panel regressions with cross-sectional dependence. The Stata Journal, 7(3), 281-312.

International Energy Agency (IEA)(2010a), Co2 Emissions from fuel combustions, Highlights, OECD/IEA, Paris, France.

International Energy Outlook (2017). U.S Energy Information Administration, https://www.eia.gov/outlooks/ieo/pdf/0484(2017).pdf. 
Irandoust, M. (2016). The renewable energy-growth nexus with carbon emissions and technological innovation: Evidence from the Nordic countries. Ecological Indicators, 69, 118-125.

Lee, S., \& Chong, W. O. (2016). Causal relationships of energy consumption, price, and CO2 emissions in the US building sector. Resources, Conservation and Recycling, 107, 220226.

Li, K., Fang, L., \& He, L. (2020). The impact of energy price on CO2 emissions in China: A spatial econometric analysis. Science of The Total Environment, 706, 135942.

Li, W., Sun, W., Li, G., Jin, B., Wu, W., Cui, P., \& Zhao, G. (2018). Transmission mechanism between energy prices and carbon emissions using geographically weighted regression. Energy Policy, 115, 434-442.

Lin, B., \& Jia, Z. (2019). Impacts of carbon price level in carbon emission trading market. Applied Energy, 239, 157-170.

Lin, B., Omoju, O. E., \& Okonkwo, J. U. (2015). Impact of industrialisation on CO2 emissions in Nigeria. Renewable and Sustainable Energy Reviews, 52, 1228-1239.

Linn, J. (2009). Why do energy prices matter? The role of interindustry linkages in US manufacturing. Economic Inquiry, 47(3), 549-567.

Mahadevan, R., \& Asafu-Adjaye, J. (2007). Energy consumption, economic growth and prices: A reassessment using panel VECM for developed and developing countries. Energy Policy, 35(4), 2481-2490.

Martinsen, D., Krey, V., \& Markewitz, P. (2007). Implications of high energy prices for energy system and emissions - the response from an energy model for Germany. Energy Policy, 35(9), 4504-4515.

Nathaniel, S. P., \& Iheonu, C. O. (2019). Carbon dioxide abatement in Africa: The role of renewable and non-renewable energy consumption. Science of the Total Environment, 679, 337-345.

Paramati, S., Mo, D., \& Gupta, R. (2017). The effects of stock market growth and renewable energy use on $\mathrm{CO} 2$ emissions: Evidence from G20 countries. Energy Economics, 66, 360-371.

Pata, U. (2018). Renewable energy consumption, urbanization, financial development, income and $\mathrm{CO} 2$ emissions in Turkey: Testing EKC hypothesis with structural breaks. Journal of Cleaner Production, 187, 770-779.

Pesaran, H. M. (2004). General diagnostic tests for cross-sectional dependence in panels. University of Cambridge, Cambridge Working Papers in Economics, 435.

Pesaran, M. H. (2006). Estimation and inference in large heterogeneous panels with a multifactor error structure. Econometrica, 74(4), 967-1012.

Pesaran, M. H. (2007). A simple panel unit root test in the presence of cross-section dependence. Journal of Applied Econometrics, 22, 265-312. https://doi.org/10.1002/jae

Pesaran, M. H., \& Smith, R. (1995). Estimating long-run relationships from dynamic heterogeneous panels. Journal of econometrics, 68(1), 79-113.

Schmalensee, R., \& Stavins, R. (2015). Lessons learned from three decades of experience with cap-and-trade. https://academic.oup.com/reep/article/11/1/59/3066276

Shahbaz, M., Solarin, S., Sbia, R., \& Bibi, S. (2015). Does energy intensity contribute to CO2 emissions? A trivariate analysis in selected African countries. Ecological Indicators, 50, 215-224.

Stiglitz, J. E., Sen, A., \& Fitoussi, J. P. (2017). Report by the commission on the measurement of economic performance and social progress. Commission on the Measurement of Economic Performance and Social Progress, Paris. 
Sun, C., Ding, D., Fang, X., Zhang, H., \& Li, J. (2019). How do fossil energy prices affect the stock prices of new energy companies? Evidence from Divisia energy price index in China's market. Energy, 169, 637-645.

Tang, C. F., \& Tan, E. C. (2013). Exploring the nexus of electricity consumption, economic growth, energy prices and technology innovation in Malaysia. Applied Energy, 104, 297-305.

Triguero, A., Moreno-Mondéjar, L., \& Davia, M. A. (2014). The influence of energy prices on adoption of clean technologies and recycling: Evidence from European SMEs. Energy Economics, 46, 246-257.

Tvinnereim, E., \& Mehling, M. (2018). Carbon pricing and deep decarbonisation. Energy Policy, 121, 185-189.

Valadkhani, A., Babacan, A., \& Dabir-Alai, P. (2014). The impacts of rising energy prices on non-energy sectors in Australia. Economic Analysis and Policy, 44(4), 386-395.

Valizadeh, J., Sadeh, E., Javanmard, H., \& Davodi, H. (2017). The effect of energy prices on energy consumption efficiency in the petrochemical industry in Iran. Alexandria Engineering Journal, 57(4), 2241-2256.

Verbič, M., Filipović, S., \& Radovanović, M. (2017). Electricity prices and energy intensity in Europe. Utilities Policy, 47, 58-68.

Wang, S., Wang, J., \& Zhou, Y. (2018). Estimating the effects of socioeconomic structure on $\mathrm{CO} 2$ emissions in China using an econometric analysis framework. Structural Change and Economic Dynamics, 47, 18-27.

WDI. (2016). The World Bank World Development Indicators. from World Bank http://data.worldbank.org/data-catalog/world-developmentindicators

World Bank (2000). Fuel for Thought: An Environmental Strategy for the Energy Sector. World Bank. Washington, D.C.: The World Bank.

Yamineva, Y., \& Liu, Z. (2019). Cleaning the air, protecting the climate: Policy, legal and institutional nexus to reduce black carbon emissions in China. Environmental Science \& Policy, 95, 1-10.

Yu, Y., \& Du, Y. (2019). Impact of technological innovation on CO2 emissions and emissions trend prediction on 'New Normal'economy in China. Atmospheric Pollution Research, 10(1), 152-161.

Yuan, C., Liu, S., \& Wu, J. (2010). The relationship among energy prices and energy consumption in China. Energy Policy, 38(1), 197-207.

Zhang, S., Hu, T., Li, J., Cheng, C., Song, M., Xu, B., \& Baležentis, T. (2019). The effects of energy price, technology, and disaster shocks on China's Energy-EnvironmentEconomy system. Journal of Cleaner Production, 207, 204-213.

Zhao, X., Ma, Q., \& Yang, R. (2013). Factors influencing CO2 emissions in China's power industry: Co-integration analysis. Energy Policy, 57, 89-98.

Zhou, K., \& Li, Y. (2019). Carbon finance and carbon market in China: Progress and challenges. Journal of Cleaner Production, 214, 536-549.

\section{Authors' Biographies}

Dr. Bamanga Umar is a lecturer at Modibbo Adama University of Technology in Yola, Nigeria. He holds a PhD in Finance from University Utara Malaysia and Master of Science (MSc) from University of Nigeria, Nsukka. He has publications in local and international journals. His areas of research include financial markets, financial economics, and energy finance. 
Dr. Md. Mahmudul Alam is an Associate Professor of Finance at Universiti Utara Malaysia and an Associate Fellow at University Technology MARA (Malaysia). He was awarded the AFFP Research Fellowship from FS-UNEP Centre (Germany) and recognised by the BDRC (USA) as one of the "Top Bangladesh Development Researchers of the Millennium". He obtained his PhD and Master's degrees from National University of Malaysia. To date he has published 130+ journal articles and presented 100+ articles at conferences. His research areas include sustainable finance, sustainable development, ecological economics, financial economics, fintech, and Islamic finance and economics.

Dr. Abul Quasem Al-Amin is a Professor at the Institute of Energy Policy and Research (IEPRe), Universiti Tenaga Nasional (UNITEN), Malaysia and MSCP Fellow at the Massachusetts Institute of Technology, USA. He also holds positions as a Visiting Professor at the Faculty of Environment, University of Waterloo, and AH International Business School (AHIBS), Universiti Teknologi Malaysia. His research areas include environmental modelling, sustainable development, and climate change. Previous projects have included climate change research with UNDESA as well as Asia Pacific Network \& Institute for Global Environmental Strategies. He holds a $\mathrm{PhD}$ in Development and Environment Studies from Universiti Kebangsaan Malaysia and Post Doc from UTM-MiT. 